\title{
Estaquia da cultivar de tomateiro Yoshimatsu
}

\author{
Luziane V de Souza; Daniel Felipe de O Gentil \\ UFAM-FCA, Av. Gal. Rodrigo OJ Ramos 3000, 69077-000 Manaus-AM; luzziane@yahoo.com.br; dfgentil@ufam.edu.br
}

\section{RESUMO}

O tomateiro 'Yoshimatsu', desenvolvido para as condições amazônicas, apresenta resistência à Ralstonia solanacearum. $\mathrm{O}$ acesso às suas sementes é limitado, podendo a estaquia contribuir para a produção de mudas. Objetivou-se verificar a influência do tipo e tamanho de estacas herbáceas na qualidade das mudas dessa cultivar. $\mathrm{O}$ experimento foi conduzido na Universidade Federal do Amazonas, em Manaus-AM. O delineamento experimental foi inteiramente casualizado, em esquema fatorial $2 \times 3$ (dois tipos de estacas: apicais e subapicais; três comprimentos de estacas: $10 ; 15$ e $20 \mathrm{~cm}$ ), com quatro repetições de 10 estacas cada. As plantas-matrizes foram cultivadas no sistema convencional. Aos 60 dias do transplante, ramos foram cortados conforme os tratamentos pré-estabelecidos. As estacas resultantes foram plantadas em copos plásticos, contendo substrato comercial, e mantidas em telado com 50\% de sombreamento. Após 30 dias do plantio, foram avaliadas as variáveis de sobrevivência (\% de estacas brotadas, enraizadas e mortas) e as variáveis de vigor (número de brotações por estaca, massa seca das brotações e das raízes). De modo geral, as estacas brotadas foram $90 \%$ ou mais, as enraizadas foram superior a $95 \%$ e as mortas inferior a $5 \%$. As estacas de $15 \mathrm{~cm}$ mostraram maior acúmulo de massa seca das brotações $(0,49 \mathrm{~g})$. As estacas apicais de 15 e $20 \mathrm{~cm}$ e subapicais de $20 \mathrm{~cm}$ apresentaram maior número de brotações (média de duas brotações por estaca). Em relação aos tipos de estacas, tanto as variáveis de sobrevivência quanto as variáveis de vigor evidenciaram que o emprego de estacas apicais ou subapicais não causou prejuízos à qualidade das mudas produzidas. As estacas herbáceas de tomateiro 'Yoshimatsu' apresentam facilidade de enraizamento e brotamento, mas as características tipo e tamanho das estacas devem ser observadas na produção de mudas. Assim, devem ser usadas estacas de 15 ou $20 \mathrm{~cm}$ de comprimento, tanto apicais quanto subapicais, pois resultaram em mudas de maior vigor.

Palavras-chave: Solanum lycopersicum, propagação vegetativa, produção de mudas.

\section{ABSTRACT}

\section{Cutting of 'Yoshimatsu' tomato}

The 'Yoshimatsu' tomato plant, developed for Amazonian conditions, is resistant to Ralstonia solanacearum. Since the access to the seeds is limited, cuttings may contribute to the production of seedlings. This study aimed to investigate the influence of type and size of herbaceous cuttings upon the quality of seedlings of this cultivar. The experiment was carried out at the Federal University of Amazonas, in Manaus, Amazon state, Brazil. The experimental design was entirely randomized in a $2 \times 3$ factorial scheme (two types of cuttings: apical and sub apical; and three lengths: 10; 15 and $20 \mathrm{~cm}$ ), with four replications of 10 cuttings each. The mother plants were grown in the conventional system. Sixty days after transplantation, branches were cut according to pre-established treatments. The resulting cuttings were planted in plastic cups containing commercial substrate and kept in a greenhouse with $50 \%$ shade. Thirty days after planting, the variables were evaluated for survival (number of sprouted, rooted and dead cuttings) and vigor (number of shoots per cutting and dry mass of shoots and roots). Overall, the percentage was $90 \%$ and higher for sprouted cuttings, $95 \%$ and higher for rooted cuttings and less than $5 \%$ for dead cuttings. The $15 \mathrm{~cm}$ cuttings showed greater accumulation of dry mass in shoots $(0.49 \mathrm{~g})$. Fifteen and $20 \mathrm{~cm}$ apical cuttings and $20 \mathrm{~cm}$ sub apical cuttings showed a higher number of shoots (average of two shoots per cutting). As for the kinds of cuttings, both survival and vigor variables showed that the use of apical or sub apical cuttings caused no damage to the quality of the seedlings produced. Herbaceous cuttings of the 'Yoshimatsu' tomato plant have shown easy rooting and sprouting, but characteristics such as type and size of the cuttings need to be considered before the production of seedlings. Therefore, cuttings of 15 or $20 \mathrm{~cm}$ in length, both apical and subapical, should be used since they have produced greater seedling vigor.

Keywords: Solanum lycopersicum, vegetative propagation, seedlings production.

\section{(Recebido para publicação em 18 de novembro de 2011; aceito em 5 de fevereiro de 2013) (Received on November 18, 2011; accepted on February 5, 2013)}

$\mathrm{O}$ tomateiro (Solanum lycopersicum) é espécie cosmopolita originária da parte ocidental da América do Sul e levada para a Europa pelos espanhóis (Murayama, 1973). No Brasil, a cultura foi introduzida possivelmente pelos portugueses (Madeira et al., 2008).

O melhoramento do tomateiro no Brasil, segundo Marangoni (2007), teve início entre colonos japoneses, resultando na formação do Grupo Santa Cruz.
Em 1969, o Instituto Agronômico de Campinas lançou oficialmente a primeira cultivar de mesa denominada Ângela, pertencente ao Grupo Santa Cruz (Melo et al., 2009). Posteriormente, ocorreu o surgimento de novas cultivares com grande importância comercial, como Santa Clara e Débora (Filgueira, 2003; Andreuccetti et al., 2005). Porém, o melhoramento dessas cultivares foi direcionado para regiões de clima favorável ao cultivo da espécie, que consiste em temperaturas amenas e umidades relativas mais baixas.

O estado do Amazonas possui temperaturas e umidades relativas elevadas, que favorecem o aparecimento de doenças fúngicas e bacterianas (Filgueira, 2003). Segundo Pahlen (1979), em toda a faixa tropical do mundo, a cultura do tomate apresenta diversos problemas, devido ser suscetível a doenças e pragas 
comuns nessa região. Uma das principais doenças que afetam o tomateiro é a murcha-bacteriana, causada por Ralstonia solanacearum, sendo considerada limitante ao cultivo no estado do Amazonas, podendo causar graves prejuízos (Noda et al., 1986).

Com o objetivo de produzir tomate em regiões de temperaturas elevadas, o Instituto Nacional de Pesquisa da Amazônia (INPA), iniciou um Programa de Melhoramento Genético para a espécie, sob coordenação do Dr. Hiroshi Noda, em 1976. Com a introdução de genes de resistência ao patógeno Ralstonia solanacearum provenientes de variedades não comerciais do estado do Hawaii (EUA) e da Guiana Francesa, em 1988, surgiu a cultivar de tomateiro Yoshimatsu (Noda et al., 1986). Contudo, esta cultivar ainda é pouco conhecida pelos pequenos produtores do estado e o acesso a sementes para a produção de mudas é bastante limitado. De acordo com Fernandes et al. (2004), a produção convencional de mudas de tomateiro é feita via semente, sendo o enraizamento por estaca pouco comum para a propagação comercial dessa espécie.

Alguns estudos mostraram ser possível a produção de mudas de tomateiro por estaquia de ramos. Fernandes et al. (2004), estudando a produção de mudas de tomateiro por meio de estacas enraizadas, em hidroponia, observaram que a propagação vegetativa é viável, podendo ser empregadas estacas oriundas de diferentes partes da planta-matriz, além de ser uma alternativa para reduzir o custo de produção. Cheng \& Chu (2002b), comparando o hábito de frutificação e a produtividade do tomateiro propagado sexuada e assexuadamente, observaram que as mudas de ponteira tiveram desempenho em qualidade e quantidade igual ao da planta-mãe. Nesse mesmo estudo, os autores verificaram que o custo de produção de mudas por meio do enraizamento de ponteiras é acessível aos tomaticultores pelo fato do pegamento ser próximo a $100 \%$.

A capacidade da estaca de ramos emitir raízes é função de fatores endógenos e das condições ambientais proporcionadas ao enraizamento. Assim, Fachinello et al. (1994) classificaram os fatores que afetam o enraizamento em internos e externos. Os fatores internos são condição fisiológica da planta-matriz, idade da planta-matriz, tipo de estacas, potencial genético de enraizamento, sanidade, balanço hormonal e oxidação de compostos fenólicos. Os fatores externos são temperatura, luz, umidade e substrato. É importante que se conheçam os fatores que afetam a formação de raízes para explicar o motivo da facilidade ou dificuldade de enraizamento. Ademais, o manejo adequado das estacas permite que haja mais chance de sucesso na produção de mudas por estaquia.

O tipo de estacas mais adequado varia com a espécie ou com a cultivar. Como a composição do tecido varia ao longo do ramo, estacas provenientes de diferentes porções do mesmo tendem a diferir quanto à porcentagem de enraizamento. Assim, estacas mais lignificadas geralmente apresentam maior dificuldade de enraizamento do que estacas de consistência mais herbácea e semilenhosa (Fachinello et al., 2005).

Em cada tipo de estacas, deve ser considerado o tamanho dos fragmentos a serem enraizados. Isto porque, quanto maior o tamanho, maior será o número de gemas e, possivelmente, maior a quantidade de reservas nutritivas para formação das raízes adventícias (Gentil \& Ascuí, 2008). Entretanto, o aumento no tamanho tende a reduzir o número de estacas obtidas de uma determinada planta-matriz, a aumentar as possibilidades de danos a esses fragmentos e a dificultar o manejo e o transporte do material propagativo.

A propagação por estaquia do tomateiro 'Yoshimatsu' pode contribuir para aumentar a difusão da cultivar na região amazônica, por facilitar a sua multiplicação pelos próprios produtores e diminuir a dependência por sementes. Diante do exposto, objetivou-se com este trabalho verificar a influência do tipo e do tamanho de estacas herbáceas sobre a qualidade das mudas da cultivar de tomateiro Yoshimatsu, em Manaus-AM.

\section{MATERIAL E MÉTODOS}

O experimento foi conduzido na
Universidade Federal do Amazonas, em Manaus $\left(3^{\circ} 13^{\prime} \mathrm{S}, 60^{\circ} 02^{\prime} \mathrm{O}\right.$, altitude 72 $\mathrm{m})$, de março a junho de 2009. O clima da região, conforme a classificação de Köppen, é do tipo Afi - tropical chuvoso. No período de realização do ensaio, as médias mensais de pluviosidade, umidade relativa do ar, temperaturas mínima, média e máxima foram $210 \mathrm{~mm}, 87,5 \%$, $22,5^{\circ} \mathrm{C}, 27^{\circ} \mathrm{C}$ e $32,5^{\circ} \mathrm{C}$, respectivamente (INMET, 2012).

Sementes do tomateiro 'Yoshimatsu' foram adquiridas no INPA, sendo que o cultivo das plantas fornecedoras de estacas foi realizado no sistema convencional, em área de terra firme com solo latossolo amarelo distrófico. Inicialmente, foi realizada a limpeza da área, que apresentava vegetação do tipo capoeira, e posteriormente a abertura e adubação das covas, com três litros de esterco bovino, aos 30 dias antes do plantio das mudas.

As mudas foram produzidas em casa de vegetação coberta com agrofilme de $150 \mu \mathrm{m}$ de espessura. A semeadura foi feita em copos de jornal $(10 \times 8 \mathrm{~cm})$, contendo substrato comercial Plantmax $^{\circledR}$ Hortaliças HT, distribuindo duas sementes por recipiente. A irrigação foi realizada diariamente pela manhã, exceto em dias chuvosos.

As mudas foram transplantadas quando apresentaram $8-13 \mathrm{~cm}$ de altura e 4-6 folhas definitivas, sendo colocadas 1-2 plantas por cova no espaçamento de 1,0 x 0,6 m. A irrigação foi realizada diariamente pela manhã e pela tarde, exceto em dias chuvosos. Os tratos culturais e fitossanitários foram conduzidos de acordo com as recomendações de Filgueira (2003).

Aos 60 dias do transplante, ramos foram retirados das plantas-matrizes, cortados em segmentos de $10 ; 15$ e 20 cm de comprimento e separados conforme a sua posição no ramo, em apicais e subapicais. As estacas foram plantadas em copos plásticos com capacidade de $500 \mathrm{~mL}$, com quatro furos de $4 \mathrm{~mm}$ de diâmetro na parte inferior, contendo o substrato Plantmax ${ }^{\circledR}$ Hortaliças HT. No plantio, as estacas foram enterradas no substrato até a metade do seu comprimento. Os copos foram mantidos em telado com 50\% de sombreamento, sobre bancada de madeira de $1 \mathrm{~m}$ de 
altura do solo. A irrigação foi efetuada no substrato antes e depois do plantio das estacas, e diariamente pela manhã, exceto em dias chuvosos.

Após 30 dias do plantio das estacas, as mudas foram retiradas do substrato e avaliadas quanto a sobrevivência e vigor. As variáveis de sobrevivência avaliadas foram números de estacas brotadas, enraizadas e mortas, sendo expressas em porcentagem. As variáveis de vigor analisadas foram número de brotações por estaca, massa seca das brotações e das raízes, sendo expressas em gramas.

A determinação da massa seca foi realizada por meio da secagem em estufa a $75^{\circ} \mathrm{C}$, durante 48 horas, e pesagem em balança analítica digital, com sensibilidade de 0,01 g. Antes da determinação, as raízes foram lavadas em água corrente sobre peneira.

O delineamento experimental utilizado foi inteiramente casualisado, em esquema fatorial $2 \times 3$ (dois tipos de estacas, quanto à posição nos ramos: apicais e subapicais; e três tamanhos de estacas: $10 ; 15$ e $20 \mathrm{~cm}$ ), com quatro repetições de 10 estacas cada. Na análise estatística, os dados foram transformados em $\sqrt{\mathrm{x}}$ para atender a afirmação de normalidade (teste de Lilliefors) e homogeneidade (teste de Cochran) (Santana \& Ranal, 2006). Os dados foram submetidos à análise de variância, sendo as médias comparadas pelo teste de Tukey, a 5\% de probabilidade. Foi utilizado o software estatístico SAEG v.9.1 (UFV, 2007).

\section{RESULTADOS E DISCUSSÃO}

As análises de variância não detectaram diferenças significativas entre os tipos e os tamanhos de estacas usados e nem interação entre os fatores avaliados para as variáveis de sobrevivência números de estacas brotadas, de estacas enraizadas e de estacas mortas (Tabela 1).

$\mathrm{Na}$ variável número de estacas brotadas, as estacas apicais apresentaram desempenho ligeiramente superior ao das estacas subapicais. Em relação aos tamanhos, as estacas com $10 \mathrm{~cm}$ de comprimento mostraram desempenho inferior em relação ao dos demais tratamentos. De qualquer modo, a porcen- tagem de estacas brotadas foi igual ou superior a $90 \%$ em todos os tratamentos.

Quanto ao número de estacas enraizadas, não houve diferença entre as médias para os tipos testados, sendo ambas iguais a 98,3\%. As estacas de $10 \mathrm{~cm}$ de comprimento apresentaram desempenho inferior ao das demais. Por outro lado, as estacas de $15 \mathrm{~cm}$ de comprimento mostraram maior valor de enraizamento (100\%).

Para a variável-resposta estacas mortas, não houve diferença entre os tipos de estacas, com médias de 1,7\%. As estacas de $10 \mathrm{~cm}$ de comprimento apresentaram valor superior ao dos demais tamanhos, com mortalidade de 3,8\%.

Os dados das variáveis de sobrevivência confirmaram a facilidade de enraizamento e de brotações de estacas de tomateiro, corroborando com as citações de Cheng \& Chu (2002a, b), Fernandes et al. (2004) e Braun et al. (2007). A capacidade de emissão de raízes adventícias da espécie já havia sido mencionada por Filgueira (2003), o que justifica, inclusive, a prática da amontoa em cultivos tutorados.

Segundo Fernandes et al. (2007), nas estacas de tomateiro, o nível interno de hormônio e substâncias relacionadas ao enraizamento é suficiente para permitir a propagação vegetativa dessa cultura sem aplicação de reguladores de crescimento. Conforme Cheng \& Chu (2002b), o custo de produção de mudas por meio do enraizamento de estacas é competitivo e conveniente para os tomaticultores, porque o pegamento é geralmente próximo a $100 \%$.

No número de brotações por estaca (Tabela 2), houve interação entre os fatores estudados. No fator tipos de estacas, dentro das estacas apicais, as de 15 e $20 \mathrm{~cm}$ de comprimento apresentaram valores estatisticamente superiores (em média, duas brotações) ao das estacas de $10 \mathrm{~cm}$ de comprimento. Dentro das estacas subapicais, as de $20 \mathrm{~cm}$ de comprimento mostraram valores significativamente superiores (em média, duas brotações) aos dos demais tamanhos. Para tamanhos de estacas, foi verificada diferença significativa somente dentro das estacas de $15 \mathrm{~cm}$ de comprimento, em que as apicais apresentaram desempenho superior, com média de duas brotações por estaca.

De acordo com a análise de variância, não houve diferença significativa e nem interação entre os tamanhos e os tipos de estacas, para a variável de vigor massa seca das brotações (Tabela 2). No entanto, quanto aos tipos de estacas, as subapicais apresentaram maior valor nesta variável-resposta $(0,69 \mathrm{~g})$; quanto aos tamanhos de estacas, as de $15 \mathrm{~cm}$ de comprimento apresentaram melhor desempenho $(0,49 \mathrm{~g})$.

Para massa seca das raízes (Tabela 2), houve interação entre os fatores estudados, mas não foi verificada diferença significativa dentro dos níveis do fator tipos de estacas. Para tamanho da estaca, dentro das estacas de 10 e $20 \mathrm{~cm}$ de comprimento, as subapicais mostraram melhor desempenho em relação às apicais, com 0,08 e 0,12 g, respectivamente. Por outro lado, dentro das estacas de $15 \mathrm{~cm}$ de comprimento, não foi detectada diferença significativa entre os dois tipos de estacas.

Em relação aos tamanhos de estacas, de modo geral, nas variáveis de sobrevivência, as estacas de $10 \mathrm{~cm}$ de comprimento apresentaram desempenho

Tabela 1. Valores das variáveis de sobrevivência de mudas de tomateiro 'Yoshimatsu', em função do tipo e tamanho das estacas (survival variables values for 'Yoshimatsu' tomato seedlings depending on the type and size of the cuttings). Manaus, UFAM, 2009.

\begin{tabular}{llcrc}
\hline \multirow{2}{*}{$\begin{array}{l}\text { Sobrevivência } \\
(\boldsymbol{\%})\end{array}$} & Tipos de & \multicolumn{3}{c}{ Tamanhos das estacas (cm) } \\
\cline { 3 - 5 } & estacas & $\mathbf{1 0}$ & $\mathbf{1 5}$ & $\mathbf{2 0}$ \\
\hline \multirow{2}{*}{ estacas brotadas } & Apical & 92,5 & 95,0 & 100,0 \\
& Subapical & 87,5 & 95,0 & 90,0 \\
\hline \multirow{2}{*}{ estacas enraizadas } & Apical & 95,0 & 100,0 & 100,0 \\
& Subapical & 97,5 & 100,0 & 97,5 \\
\hline \multirow{2}{*}{ estacas mortas } & Apical & 5,0 & 0,0 & 0,0 \\
& Subapical & 2,5 & 0,0 & 2,5 \\
\hline
\end{tabular}


Tabela 2. Valores ${ }^{1}$ das variáveis de vigor das mudas de tomateiro 'Yoshimatsu', em função do tipo e do tamanho das estacas (vigor variables values for 'Yoshimatsu' tomato seedlings depending on the type and size of the cuttings). Manaus, UFAM, 2009.

\begin{tabular}{lllcc}
\hline \multirow{2}{*}{ Vigor } & Tipos de & \multicolumn{3}{c}{ Tamanhos das estacas (cm) } \\
\cline { 3 - 5 } & estacas & $\mathbf{1 0}$ & $\mathbf{1 5}$ & $\mathbf{2 0}$ \\
\hline \multirow{2}{*}{ Brotações por estaca $\left(\mathrm{n}^{\mathrm{o}}\right)$} & Apical & $1,3 \mathrm{Ba}$ & $2,0 \mathrm{Aa}$ & $1,9 \mathrm{Aa}$ \\
& Subapical & $1,1 \mathrm{Ba}$ & $1,3 \mathrm{Bb}$ & $2,0 \mathrm{Aa}$ \\
\hline \multirow{2}{*}{ Massa seca das brotações $(\mathrm{g})$} & Apical & 0,04 & 0,23 & 0,09 \\
& Subapical & 0,70 & 0,75 & 0,61 \\
\hline \multirow{2}{*}{ Massa seca das raízes $(\mathrm{g})$} & Apical & $0,07 \mathrm{~b}$ & $0,09 \mathrm{a}$ & $0,08 \mathrm{~b}$ \\
& Subapical & $0,08 \mathrm{a}$ & $0,10 \mathrm{a}$ & $0,12 \mathrm{a}$ \\
\hline
\end{tabular}

${ }^{1}$ Em cada variável-resposta, médias seguidas de mesma letra minúscula na coluna e de mesma letra maiúscula na linha não diferem entre si, pelo teste de Tukey, a 5\% de probabilidade (in each response variable, averages followed by the same lowercase letter in a column and uppercase letter in a row do not differ one from another in the Tukey test at 5\% probability, $\mathrm{p}<0.05)$.

ligeiramente inferior. Possivelmente, devido à menor quantidade de reservas nesse tipo de estaca. Na variável de vigor massa seca das brotações, as estacas de $15 \mathrm{~cm}$ mostraram maior acúmulo de massa seca. No número de brotações, as estacas apicais de 15 e $20 \mathrm{~cm}$ de comprimento apresentaram maior número de brotações, enquanto que nas subapicais o maior número de brotações foi registrado nas estacas de $20 \mathrm{~cm}$. Fernandes et al. (2007) também recomendam o comprimento da estaca de 15 a $20 \mathrm{~cm}$ para o híbrido de tomateiro Carmem.

O tamanho da estaca é fator relevante na qualidade das mudas de tomateiro. De acordo com Braun et al. (2007), estacas com maiores comprimentos possuem maior conteúdo de carboidratos que poderá ser utilizado na manutenção de maior taxa de crescimento inicial das mudas, formando primeiramente raízes e folhas novas para iniciar o processo fotossintético, aumentando as fontes de carboidratos que poderão ser utilizadas para a manutenção e o desenvolvimento das mudas.

Em relação aos tipos de estacas, tanto as variáveis de sobrevivência quanto as de vigor evidenciaram que o emprego de estacas apicais ou subapicais não causou prejuízos à qualidade das mudas produzidas. Segundo Fernandes et al. (2004), a propagação vegetativa do tomateiro é viável, podendo-se empregar estacas oriundas de diferentes posições na planta-matriz.

Usando a multiplicação via pro- pagação vegetativa, um programa de melhoramento genético de tomateiro pode ser concluído em menos de dois anos, economizando tempo, recursos humanos e financeiros, em comparação com os métodos tradicionais via propagação por sementes botânicas (Cheng \& Chu, 2002a).

A propagação vegetativa do tomateiro por enraizamento de estacas pode facilitar a obtenção de mudas sem grandes ônus para o pequeno produtor. Segundo Cheng \& Chu (2002b), do ponto de vista econômico, as mudas produzidas por via assexuada poderão abrir um novo nicho de mercado para as firmas produtoras de mudas, com certificação das mesmas, sem doenças e pragas, de modo semelhante ao que ocorre com a batata-semente. Ademais, Fernandes et al. (2007) salientam que a propagação vegetativa do tomateiro é alternativa para a redução dos custos de produção de mudas e a estaquia é a técnica de maior viabilidade para o estabelecimento de plantios clonais, por permitir a multiplicação de genótipos selecionados, em curto período, a um menor custo.

Os resultados evidenciaram que as estacas herbáceas de tomateiro 'Yoshimatsu' apresentam facilidade de enraizamento e brotamento. Mas, as características tipo e tamanho das estacas devem ser observadas na produção de mudas. Desse modo, recomenda-se usar estacas de 15 ou $20 \mathrm{~cm}$ de comprimento, tanto apicais quanto subapicais, pois resultaram em mudas de maior vigor.

\section{AGRADECIMENTOS}

À Fundação de Amparo à Pesquisa do Estado do Amazonas (FAPEAM), pela concessão de bolsa de mestrado ao primeiro autor.

\section{REFERÊNCIAS}

ANDREUCCETTI C; FERREIRA MD; GUTIERREZ ASD; TAVARES M. 2005. Horticultura Brasileira 23: 324-328.

BRAUN H; CAVATTI PC; AMARAL JAT; AMARAL JFT; REIS EF. 2007. Produção de mudas de tomateiro por estaquia: efeito do substrato e comprimento de estacas. Idesia 28: 9-15.

CHENG SS; CHU EY. 2002a. 'Pará Belo': um clone do tomateiro adaptado à Amazônia Oriental. Horticultura Brasileira 20: 516-519.

CHENG SS; CHU EY. 2002b. Habito de frutificação e produtividade do tomateiro propagado vegetativa e sexuadamente na Amazônia Oriental. Horticultura Brasileira 20: 664-666.

FACHINELLO JC; HOFFMANN A; NACHTIGAL JC. 2005. Propagação de plantas frutíferas. Brasília: Embrapa Informações Tecnológicas. 221p.

FACHINELLO JC; HOFFMANN A; NACHTIGAL JC; KERSTEN E; FORTES GRL. 1994. Propagação de plantas frutíferas de clima temperado. Pelotas: UFPEL. 179p.

FERNANDES AA; MARTINEZ HEP; SILVA DJH; BARBOSAJG. 2004. Produção de mudas de tomateiro por meio de estacas enraizadas em hidroponia. Pesquisa Agropecuária Brasileira 39: 343-348.

FERNANDES AA; MARTINEZ HEP; SILVA DJH; BARBOSA JG; PEDROSA DW. 2007. Cultivo sucessivo de plantas de tomate oriundas de sementes e propagação vegetativa em sistema hidropônico. Pesquisa Agropecuária Brasileira 42: 1013-1019.

FILGUEIRA FAR. 2003. Novo manual de olericultura: agrotecnologia moderna na produção e comercialização de hortaliças. Viçosa: UFV. 412p.

GENTIL DFO; ASCUÍACG. 2008. Características das estacas e qualidade de mudas de cariru. In: CONGRESSO BRASILEIRO DE OLERICULTURA, 48. Resumos... Maringá: SOB (CD-ROM).

INMET - Instituto Nacional de Meteorologia. 2012. Boletim agroclimatológico. Disponível em http://www.inmet.gov.br/html/agro.html/. Acessado em 30 de março de 2012.

MADEIRA NR; REISFSCHNEIDER FJB; GIORDANO LB. 2008. Contribuição portuguesa à produção e ao consumo de hortaliças no Brasil: uma revisão histórica. Horticultura Brasileira 26: 428-432.

MARANGONI RE. 2007. Revisão literária do melhoramento genético na cultura do tomate 
(Lycopersicon sp.). Disponível em http:// fitopatologia1.blogspot.com/2010/07/revisaoliteraria-do-melhoramento.html. Acessado em 27 de outubro de 2010.

MELO PCT; MELO AMT; ARAGÃO FAZ. 2009. Melhoramento genético de hortaliças no Brasil: retrospectiva e perspectiva. In: SIMPÓSIO NORDESTINO DE GENÉTICA E MELHORAMENTO DE PLANTAS Anais... Fortaleza: Embrapa Agroindústria
Tropical. p. 60-82.

MURAYAMA S. 1973. Horticultura. Campinas: Instituto Campineiro de Ensino Agrícola. $321 \mathrm{p}$.

NODA H; PAHLEN A; SILVA FILHO DF. 1986. Avaliação da resistência de progênie de tomate à murcha bacteriana em solo naturalmente infestado por (Pseudomonas solanacearum (Smith) Dows. Revista Brasileira de Genética 9: 55-66.
PAHLENA. 1979. Tomate. In: PAHLEN A; KERR WE; PAIVA WO; RAHMAN F; YUYAMA $\mathrm{K}$; PAHLEN E; NODA H. Introdução à horticultura e fruticultura no Amazonas. Manaus: SUFRAMA-INPA. p. 65-70.

UFV. 2007. SAEG: Sistemas de Análises Estatísticas e Genéticas. Versão 9.1. Viçosa: UFV. $150 \mathrm{p}$.

SANTANA DG; RANAL MA. 2004. Análise da germinação: um enfoque estatístico. Brasília: Editora Universidade de Brasília. 248p. 